\title{
Um olhar para Silveira Martins/RS: textos e contextos sobre saberes e fazeres locais
}

\author{
A look at Silveira Martins/RS: texts and contexts about local knowledge and practices \\ Una mirada a Silveira Martins/RS: textos y contextos sobre el conocimiento y las prácticas \\ locales
}

Ana Carla Lenz ${ }^{1}$ http://orcid.org/0000-0002-8364-3591

Cesar De David ${ }^{2}$ http://orcid.org/0000-0003-0872-9181

Natália Lampert Batista ${ }^{3}$ http://orcid.org/0000-0002-1884-2340

\footnotetext{
1 Mestre em Geografia - Universidade Federal de Santa Maria - UFSM, Santa Maria-RS- Brasil, Bolsista CAPES anacarlalenz@gmail.com

${ }^{2}$ Doutor em Geografia - Universidade Federal de Santa Catarina - UFSC- Sc-Brasil, Professor Associado da Universidade Federal de Santa Maria - UFSM - Santa Maria-RS-Brasil, cdedavid2009@gmail.com.

${ }^{3}$ Doutora em Geografia - Universidade Federal de Santa Maria - UFSM - Santa Maria-RS-Brasil, Professora de Geografia (Anos Finais) na Prefeitura Municipal de Santa Maria (PMSM)- Brasil, em Licença de Interesse Particular (Portaria n ${ }^{\circ}$ 1586/SMG de 19 de julho de 2019) - natilbatista3@gmail.com.
}

\section{Resumo}

O presente artigo discute a formação territorial do município de Silveira Martins/RS e apresenta alguns conhecimentos herdados dos imigrantes italianos, os saberes e fazeres adaptados e desenvolvidos no processo de ocupação das terras do município. Para a redação deste artigo, priorizaram-se três elementos culturais, destacados pela pesquisa: o cultivo de uva, a sangria ou carneação e a cuca. Concluiu-se que tecer um olhar sobre Silveira Martins, produzindo textos e relatando contexto, é uma forma de preservar e difundir sua cultura, bem como expor o imaginário mistificado sobre as ruralidades que não mais vigoram ou sobre àquelas que lutam cotidianamente para serem mantidas por quem domina os saberes e fazeres típicos do colonizador local e suas transformações no decorrer do tempo.

Palavras-chave: Saberes e Fazeres locais. Ruralidades. Transformações na Paisagem.

\footnotetext{
Abstract

This article discusses the territorial formation of the municipality of Silveira Martins / RS and presents some knowledge inherited from Italian immigrants, the knowledge and practices adapted and developed in the process of occupation of the municipality's lands. For the writing of this article, three cultural elements were highlighted, highlighted by the research: grape cultivation, sangria or meat and cuca. It was concluded that weaving a look at Silveira Martins, producing texts and reporting context, is a way of preserving and spreading her culture, as well as exposing the mystified imaginary about ruralities that no longer prevail or about those that struggle daily to be maintained by who masters the knowledge and practices typical of the local colonizer and their transformations over time.
} 
Keywords: Local knowledge and practice. Ruralities. Transformations in the Landscape.

\section{Resumen}

Este artículo analiza la formación territorial del municipio de Silveira Martins / RS y presenta algunos conocimientos heredados de inmigrantes italianos, los conocimientos y prácticas adaptados y desarrollados en el proceso de ocupación de las tierras del municipio. Para la redacción de este artículo, se destacaron tres elementos culturales, destacados por la investigación: cultivo de uva, sangría o carne y cuca. Se concluyó que echar un vistazo a Silveira Martins, producir textos e informar el contexto, es una forma de preservar y difundir su cultura, así como de exponer el imaginario desconcertado sobre las zonas rurales que ya no prevalecen o sobre aquellas que luchan a diario por mantenerse. Quien domina el conocimiento y las prácticas típicas del colonizador local y sus transformaciones a lo largo del tiempo.

Palabras clave: Conocimiento y práctica local. Ruralidades. Transformaciones en el paisaje.

Recebido em: 20/04/2020

Aceito para publicação em: 30/06/2020

Publicado em 21/07/2020

\section{Introdução}

Vivemos em um mundo cada vez mais conectado, via Tecnologias da Informação e Comunicação (TIC), que está transformando o modo de interação dos seres humanos, suas formas de aprender, de se comunicar e de conviver. Um significativo número de pessoas está migrando dos lugares físicos de socialização, de encontro, de troca, de ensino, de trabalho, de festa, entre outros, para espaços de socialização virtuais. O convívio, nesses espaços, é mediado por dispositivos eletrônicos, favorecendo, por vezes, a descaracterização dos grupos culturais já existentes e, também, o desenvolvimento de um "novo" modelo cultural, o cibernético. Os elementos culturais construídos ao longo do tempo, na interação homem/meio e homem/homem, vão deixando de existir ou ganham nova roupagem na era da informática.

Tomando tais constatações por base, o presente artigo emerge das discussões oriundas de uma Pesquisa de Mestrado intitulada: "Festividades religiosas e socialização em espaços rurais: o caso de Silveira Martins - RS", desenvolvida no Programa de Pós-Graduação em Geografia (PPGGeo), da Universidade Federal de Santa Maria (UFSM), defendida em janeiro de 2020. O texto discute a formação territorial do município de Silveira Martins/RS e apresenta alguns conhecimentos 
herdados dos imigrantes italianos, os saberes e fazeres adaptados dos colonizadores e desenvolvidos no processo de ocupação das terras do município.

A importância do estudo está pautada na difusão de um modo de ser e viver comunitário e na colaboração para o despertar de outro olhar para as ruralidades silveirenses, bem como para a sensibilização perante a valorização da cultura local e da agricultura familiar voltada para a policultura. Com a ciência geográfica, neste ínterim, o trabalho contribui com a corrente humanística, que se dedica a estudar as experiências das pessoas e dos agrupamentos humanos, visando entender seus valores e comportamentos, ou seja, colaborando com o que propõem Massey (2008), aquela que defende que a ciência nasce da vida.

Quanto aos procedimentos metodológicos, fez-se uso da abordagem qualitativa. Em um primeiro momento, revisitou-se a historicidade do município por meio da revisão literária e de narrativas de participantes da pesquisa. Após, foram realizadas sondagens em campo nas linhas e vilas de Silveira Martins. Ao longo do ano de 2019, realizaram-se entrevistas semi-estruturadas com os moradores locais, com os visitantes e/ou consumidores das festas locais, a fim de averiguar quais são os saberes e fazeres herdados dos imigrantes italianos ainda exercidos e consumidos pela população local e visitante. Para a redação deste artigo, priorizaram-se três elementos culturais destacas pela pesquisa: o cultivo de uva, a sangria, a cuca. Eles foram eleitos para dialogar sobre as transformações que estão ocorrendo no campo silveirense e na cultura local.

\section{Silveira Martins: textos e contextos}

A Quarta Colônia de Imigração Italiana do Rio Grande do Sul (antiga Colônia Silveira Martins), apresentada no Mapa da Figura 1, localizada na região centro-oeste do Estado, entre Santa Maria e Cachoeira do Sul, foi fundada em 19 de maio de 1877 com a vinda de imigrantes italianos oriundos das regiões do norte da Itália. Esse processo migratório se associa ao processo de ocupação das terras sulinas ${ }^{4}$ no século XIX, proposto pelo Governo Imperial Brasileiro, assim como, pela necessidade da Itália em "expulsar" para outros territórios a população expropriada do meio rural e os

\footnotetext{
${ }^{4}$ Cabe destacar que nesta época alguns lotes do território já eram habitados por alemães e poloneses.
} 
desempregados citadinos criados pela crise agrícola e urbana (MANFIO; BENADUCE, 2017).

Mapa 1- Localização da Quarta Colônia com ênfase em Silveira Martins

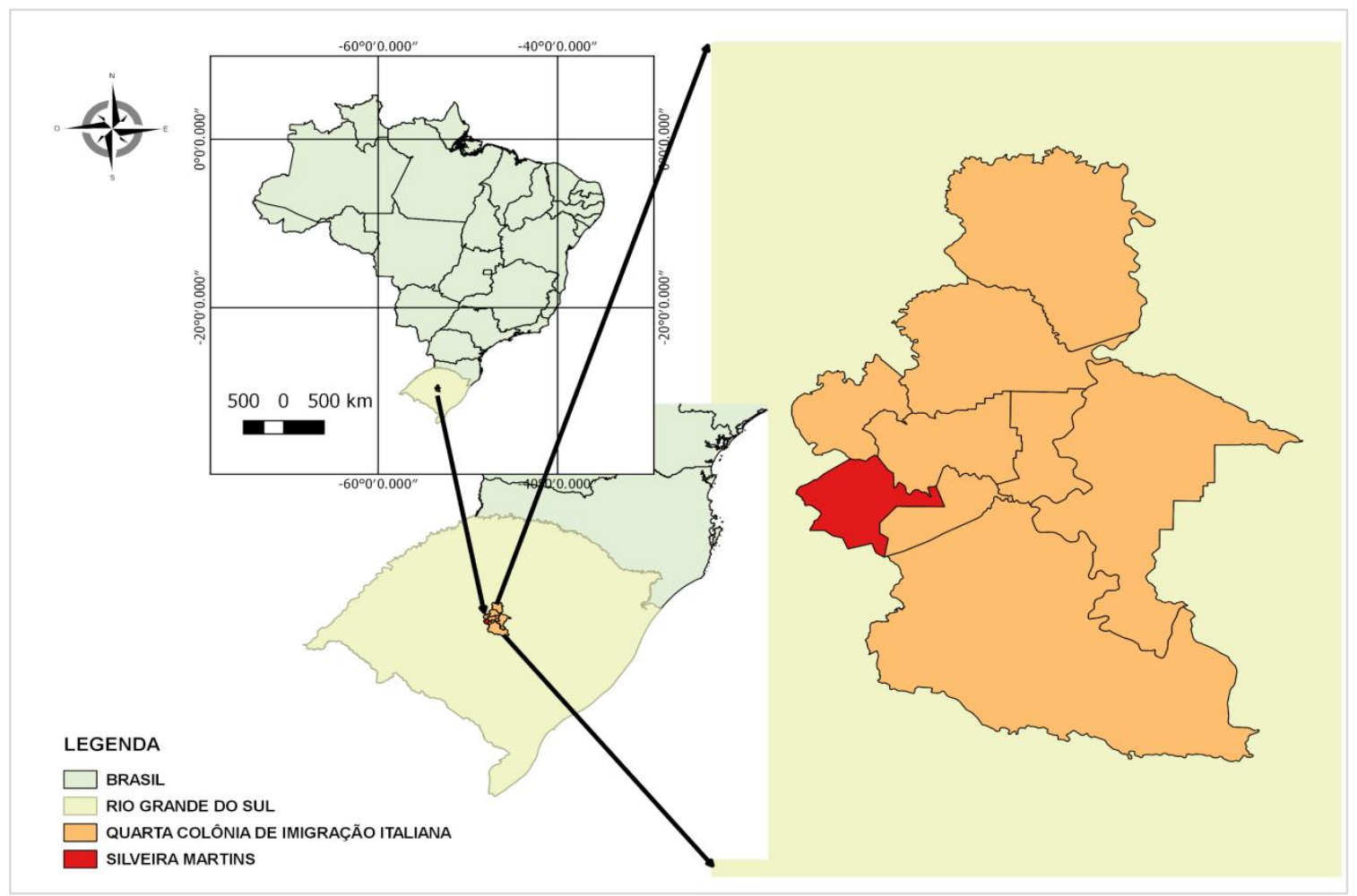

Fonte - LENZ, A. C. (2019).

Uma das razões que levaram famílias inteiras migrarem para está região foi à crise urbana italiana, estimulada pela à inserção de novas tecnologias, movidas a carvão, nos modos de produção, promovendo o aumento da industrialização na Europa e provocando a falência de várias pequenas empresas (GIRON; HERÉDIA, 2007). O país possuía uma grande população na metade do século XIX e poucas áreas cultiváveis, sem ter feito Reforma Agrária, o acesso a terra era difícil, obrigando os homens e mulheres do campo a migrarem para os centros urbanos em busca de trabalho. As cidades já não tinham como absorver tanta mão de obra. O desejo de abandonar seus patrões na Itália para se tornarem autônomos no Brasil, através da agricultura e do comércio, também foi um dos motivos que levou alguns italianos a sair de seu país de origem. Isso também está atrelado ao perfil dos migrantes colonizadores da Quarta Colônia, Pazuch (2019) destaca que a maioria deles eram pequenos agricultores, arrendatários ou jornaleiros.

O descrito se comprova com as formulações de Saquet (2002). Segundo o autor, os italianos que habitaram a Colônia Silveira Martins eram em sua maioria do norte da Itália, sendo 30,1\% de Treviso; 15,6\% de Vicenza; 10,8\% de Udinese; $10 \%$ de Verona; 
9,4\% de Trento; 7,3\% de Mântova; 6\% de Belluno e 3,5\% de Reggio Nell'Emilia. "Pode-se dizer que isso conferiu uma característica predominantemente agrícola" aos espaços geográficos ocupados por esses grupos populacionais (SAQUET, 2002, p. 38).

O município de Silveira Martins só foi emancipado em 1987 e leva o título, na atualidade, de Berço da Quarta Colônia. Os imigrantes que iniciaram a construção de Silveira Martins trouxeram na bagagem a cultura religiosa Cristã, ratificada no período medieval. Barichello (2010, p. 25-26) destaca que isso ocorreu em virtude de que "os espaços onde se efetuou a formação do pensamento Cristão foi a Península Itálica, em Santa Sé, que na atualidade corresponde ao Vaticano, ao longo dos anos o pensamento cristão se pulverizou pelas comunidades que possuíam o orgulho da italianidade em construção".

Motivo da interferência católica nas questões políticas e educacionais de Silveira Martins, de acordo com Pazuch (2019) foi que:

[...] no início, a política local, a organização social e a educação dos imigrantes e seus filhos foram dirigidas pela Igreja Católica através dos institutos religiosos das Irmãs do Imaculado Coração de Maria que fundaram a Escola Nossa Senhora de Lourdes a 25 de julho de 1882 na localidade de Vale Vêneto e dos Padres e Irmãos Palotinos que chegaram a 29 de julho de 1886 na mesma localidade. (PAZUCH, 2019, p. 4).

As famílias que fugiram das crises no período da formação do Estado Nacional Italiano e da Revolução Industrial reconstruíram suas vidas remodelando as paisagens ${ }^{5}$ através da edificação de lugares de vivência, de trabalho e de fé sobre a vegetação típica do Bioma Mata Atlântica (conjunto diversificado de formações florestais e alguns ecossistemas como manguezais, restingas e campos de altitude que se estende do Rio Grande do Norte ao Rio Grande do Sul) e do Bioma Pampa (composto por estepes, sendo que seu nome se originou do termo indígena quéchua pampa que significa planície, mas além delas se encontram serras, morros rupestres e coxilhas), modificando-os radicalmente com suas regras, rituais, mitos e ritmos de matriz cultural italiana e católica. Transferidos às novas gerações por meio de processos de ensino e aprendizagem das técnicas tradicionais de trabalho e as desenvolvidas no novo espaço

\footnotetext{
5 A paisagem é entendida aqui como “[...] um sistema territorial composto por diferentes componentes formados a partir da influência dos processos naturais e da atividade modificadora da sociedade humana, que se encontra em permanente interação e que se desenvolvem historicamente" (LOMBARDO e CASELLA, 1997, p. 92)
} 
habitado para trabalhar a terra, perpetuando o sentimento de pertencimento à identidade étnica italiana e o catolicismo entre os membros comunitários (LENZ, 2020).

A estrutura paisagística se deu de acordo com as prioridades familiares, assim, somente depois que as necessidades de moradia e alimentação eram sanadas (para os imigrantes italianos a família e o lote de terra sempre foram à prioridade), iniciava a construção dos espaços de socialização, ou seja, a capela e o seu salão. Os lugares de fé, as capelas, eram/são os espaços de sociabilidade, à época de relações primárias formadas por pequenos grupos de convivência onde as pessoas trocavam bilhetinhos segundo os entrevistados. Para Pazuch (2019), isso ocorria porque,

[...] não havia contato direto entre os moradores de cada linha, pois as linhas ficavam isoladas umas das outras, sendo que a sociabilidade dos colonos acontecia esporadicamente, quando iam à sede da linha ou da Colônia, pois durante a semana os colonos conviviam apenas com familiares e parentes em casa e no trabalho. A sociabilidade acontecia aos domingos nas Sociedades da Capela, quando os colonos se encontravam para rezar, conversar e planejar as atividades semanais, conservando assim, alguns costumes trazidos da Itália para a Colônia de Silveira Martins. (PAZUCH, 2019, p.5).

A área territorial do município de 119, $285 \mathrm{~km}^{2}$ (IBGE, 2019) e possui diferentes formas de relevo. Verifica-se a presença de três classes geomorfológicas, tendo o Rebordo do Planalto como mais representativo do território $(59,2 \%)$, seguido pelo Planalto dos Campos Gerais (39,2\%) e Depressão do Rio Jacuí (1,6\%)”. Nesse contexto, observa-se que a maior parte territorial de Silveira Martins possui declividade menor que $25^{\circ}$ (89,8\%) (ROVANI; VIEIRA, 2016, p. 154-157). As atividades predominantes nessas áreas são: a criação de bovinos e lavouras temporárias de aveia, milho e soja que demandam grandes extensões de terras e insumos agrícolas, necessitando cada vez menos de mão de obra humana, favorecendo o esvaziamento de pessoas do campo silveirense.

O município está na região fisiográfica denominada encosta da Serra de São Martinho. Não possui distritos, mas sim Linhas: Linha Base, Linha Um Sul, Linha Duas, Linha Três Sul, Linha Quarta, Linha Seis Sul, Linha Seis Norte, Linha Sete Sul e, localidades: Val Feltrina, Val de Buia, Linha dos Mantuanos, Vila Cattani, Val Veronês, Linha Pompèia e Vale dos Panos, além do centro administrativo - Sede. A configuração atual das Linhas foi desenvolvida por meio de uma organização inicial, onde os 
administradores no período, o Estado e a Igreja Católica, traçaram uma Linha Base e a partir dela iniciavam a distribuição das terras para o Norte e para o Sul.

A paisagem de Silveira Martins resultou de uma multiplicidade de fatores, como:

1. as questões políticas com o envolvimento direto da Igreja Católica Apostólica Romana na configuração espacial e na educação das novas gerações;

2. as dificuldades econômicas enfrentadas na época como a falta de alimento, sementes, ferramentas, material para a construção das residências;

3. a geografia do terreno que promoveu o isolamento das comunidades à época.

Além disso, destaca-se a inserção dos conhecimentos desenvolvidos nos textos e contextos da vida na Itália, trazidos pelos primeiros imigrantes, os quais contribuíram para a elaboração e manutenção de saberes e fazeres desenvolvidos nas práticas diárias de trabalho e de convivência no novo hábitat.

O abandono da terra natal em virtude das crises provocadas pela falta de emprego e terra para cultivar fez com que as técnicas de trabalho fossem adaptadas para modelar a nova paisagem ocupada. Na atualidade, por ironia, os que as herdaram estão passando por um processo parecido de esvaziamento do campo em virtude da inserção de novas tecnologias movidas a combustíveis fósseis e a eletricidade, bem como produzindo cenários de aproximação virtual e de segregação física. Os lugares construídos para recomeçar estão sofrendo rapidamente se transformando e lentamente desaparecendo. O principal fator, para tal contexto, é o envelhecimento da população e a falta de descendentes para perpetuarem o conhecimento herdado.

Assim, a paisagem de Silveira Martins construída por meio do trabalho humano sobre o espaço geográfico, que abrigou famílias inteiras fugidas da crise urbana italiana promovida pela inserção de novas tecnologias, agora se vê desafiada a manter os costumes e tradições de seus antepassados e a permanecerem no campo produzindo releituras dos saberes e fazeres herdados dos primeiros moradores locais. Esse desafio se pauta nas diferentes interpretações e das multiplicidades culturais e de interesses da dinâmica sociedade contemporânea que coloca como impõem novos modelos produtivos e de socialização, muitas vezes, dizimando os conhecimentos herdados do passado e outras, apropriando-se deles, como foram de "venda" de um ideário cultural local e supostamente heterogenizado. Silveira Martins teve sua constituição política e educacional moldada pela influência dos costumes italianos e pelo catolicismo, todavia, 
hoje essa realidade está se (des)configurando, muitos saberes e fazeres se perdendo e novas roupagens produtivas do mundo capitalista sendo implementadas e/ou impostas no meio rural.

\section{Os saberes e os fazeres do rural silveirense: um diálogo possível sobre a memória do e no lugar}

"É fazendo que se aprende a fazer aquilo que se deve aprender a fazer."

(Aristóteles)

A dinâmica ocupacional de Silveira Martins é marcada por saberes e fazeres desenvolvidos por meio da articulação de dois fatores: hábitos culturais trazidos na bagagem do imigrante italiano e as dificuldades enfrentadas para a adaptação das famílias à geografia do terreno, ou seja, interação homem/homem e homem/meio. Atualmente, esses elementos são encontrados nas linhas e localidades rurais do município, são conhecimentos herdados que caracterizam, principalmente, o rural, passados entre as gerações nas atividades diárias da lida no campo. Eles atribuem ao rural uma imagem de um mundo de pequenas plantações e criações e de cenários imaginários e bucólicos. Contudo, assim como ocorreu e está ocorrendo no espaço agrário brasileiro, o rural silveirense, também, sofreu e vem sofrendo com as ações e imposições do sistema capitalista se convertendo em "um espaço dinâmico que serve à produção e às trocas globalizadas" (DE DAVID, 2019, p. 278).

As ações de marketing, para a venda de produtos industrializados, fazem uso de um rural mistificado, embebido em saudosismos e memórias românticas de um passado distante e não mais coerente com a realidade do lugar. São estratégias que fomentam, entre os moradores urbanos das médias e grandes cidades, o entendimento de que o rural é a natureza intocada, que envolve as noções de tranquilidade, ar puro, sossego e descanso, mas que desconsideram as influências massivas e dinâmicas da contemporaneidade. O imaginário não leva em consideração as exaustivas rotinas de trabalho nas pequenas propriedades e as mudanças ocorridas pela modernização da agricultura, que promoveu significativas transformações nas estruturas produtivas e agrárias, devido às "alterações nas bases técnicas, nos processos de trabalho, nas 
relações sociais de produção, nas formas de apropriação da natureza, nas novas formas e conteúdos do rural, etc.” (KOZENIESKI, 2017, p.55).

Contudo, na área rural de Silveira Martins ainda existem algumas unidades de paisagem ${ }^{6}$ que ratificam a imagem de que o rural é um conjunto de elementos "naturais" àquela população. Tais locais, cada vez mais raros, lutam pela manutenção de seus modos de vida mesmo incorporando algumas facilidades e modernidades da sociedade líquida. São espaços portadores de saberes e fazeres desenvolvidos nos núcleos familiares e nos espaços de socialização, memórias do e no lugar dos primeiros colonizadores. Esses lugares são dotados de belezas cênicas, atrelada ao imaginário do homem moderno sobre as ruralidades, a qual é explorada pelo mercado econômico e vendida como paisagem idealizada, como topofília, como retorno a paz e tranquilidade do campo de outrora. Aos olhos dos consumidores, o "tradicional" das comunidades formadas pela agricultura familiar está associado a uma condição de produção historicamente desenvolvida, bem como ao imaginário religioso que envolve esses recantos de Silveira Martins, como mostra a foto1.

Foto 1 - Ruralidades de Silveira Martins/RS. 2019

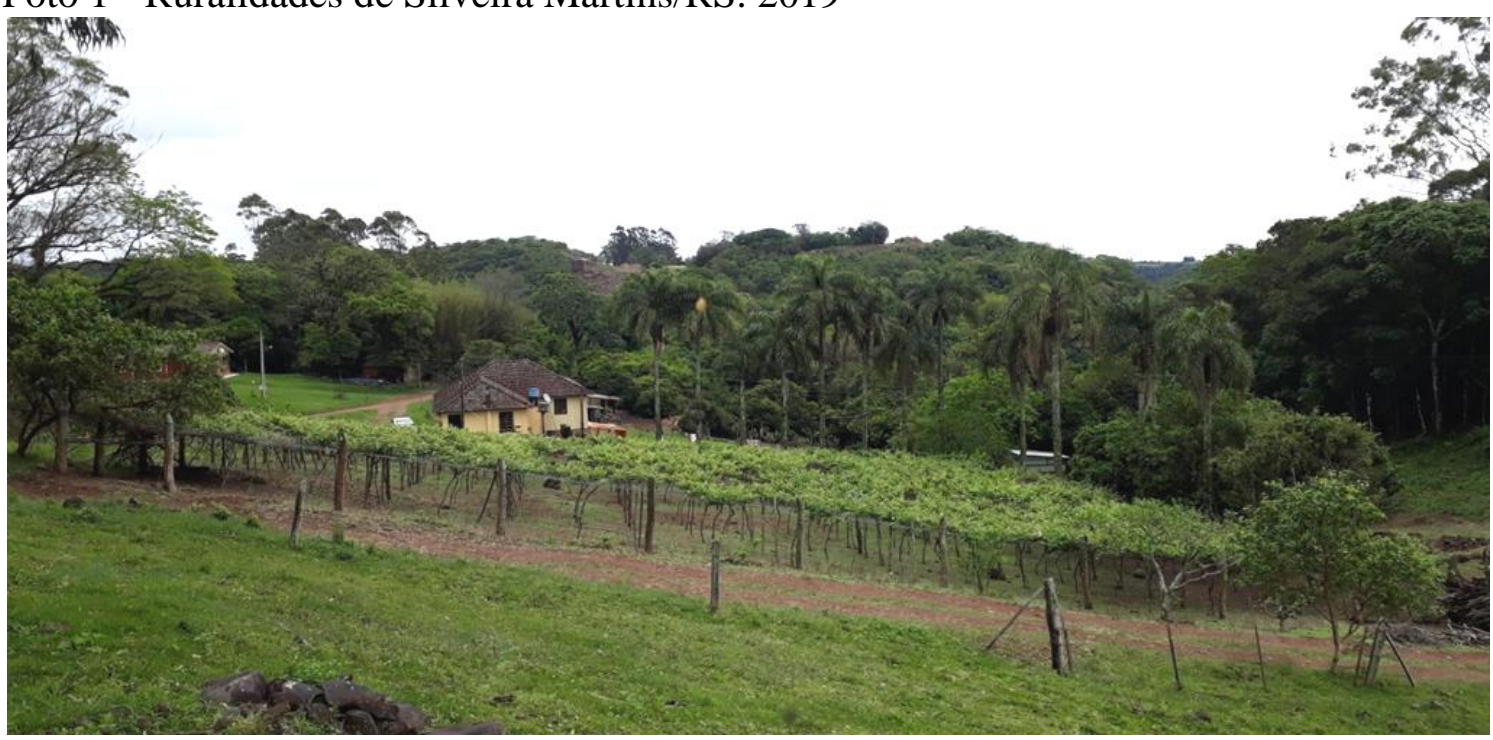

Fonte - LENZ, A. C. (Novembro de 2019. Silveira Martins/RS).

$\mathrm{Na}$ foto 1, percebe-se uma propriedade rural silveirense que ainda mantem características típicas do imaginário acerca do rural e das ruralidades de Silveira Martins/RS. A fotografia destaca as videira que remontam a produção da uva e do vinho como costumes locais.

\footnotetext{
${ }^{6}$ São lugares constituídos por elementos paisagísticos mediadores dos ciclos e das dinâmicas sociais.
} 
O cultivo de videiras está na historicidade silveirense. É um dos primeiros cultivos permanentes do município, mas com o aumento das áreas de lavouras temporárias de soja, milho, aveia, batata-inglesa e feijão, estas paisagens estão desaparecendo da paisagem, mesmo sendo constantes nos rótulos de produtos locais. Entre os relatos do depoente A, elenca-se a confirmação do observado: "não existia uma família em Silveira que não cultivasse uva, mas hoje está diminuindo muito" (Trabalho de campo, 06 de maio de 2019). As videiras eram uma das simbologias mais espacializadas da cultura local no município, por fornecer o fruto que manipulado produz a bebida típica do imigrante italiano e dos seus descendentes: o vinho.

A vitivinicultura, em algumas localidades, é uma das atividades das famílias de Silveira Martins, uma tradição transmitida entre as gerações. Para Guimarães e Pinheiro (2018, p. 46), o saber-fazer é uma forma de "expressão da cultura local que, estabelecendo relações entre atores sociais, através do conhecimento herdado e repassado de geração a geração, é capaz de promover bens e serviços com singularidades específicas", por esse motivo, no mundo contemporâneo, ao saber-fazer é atribuído valor mercantil, fato também associado em virtude de que a imaterialidade presente nesse patrimônio que é algo "socialmente construído e que se expressa pelas práticas da comunidade” (MEDEIROS; MEDEIROS; LINDNER, 2019, p.387).

Foto 2 - Pipas de vinho em Val Feltrina, Silveira Martins/RS.

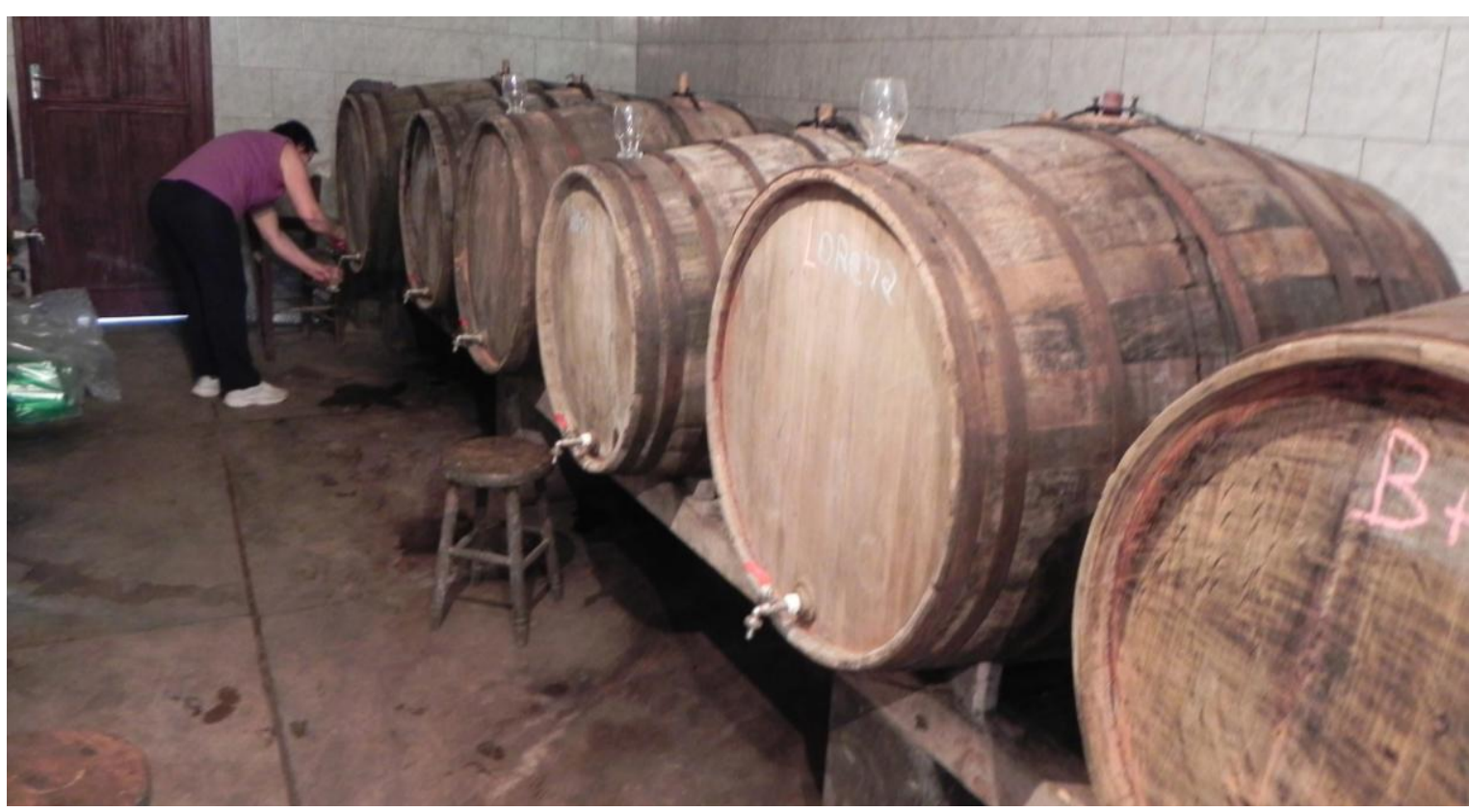

Fonte - LENZ, A. C. (Novembro de 2019. Silveira Martins/RS). 
Por esse motivo, o vinho se tornou fonte de renda para algumas famílias rurais do município. $\mathrm{O}$ entrevistado $\mathrm{A}$ incorpora aos relatos anteriores, “[...] tenho muitos clientes de Santa Maria, eles vêm comprar de mim porque sabem que a uva do meu vinho é dos meus parreirais, muitos dizem que é por isso que é mais saboroso que o do mercado, também adoram beber direto da pipa"(informação verbal) ${ }^{7}$, como revela a Foto . Isso se explica na fala de Medeiros; Medeiros e Lindner (2019, p.339), para os autores “[...] o espaço portador de valores socioculturais atua no sentido de enriquecer a identidade do vinho".

Esses valores de identificação frente aos saberes e fazeres do campo que são buscados pelos visitantes do local, ao vivenciar e ao consumir os produtos do lugar, pois para eles essas peculiaridades são "diferenças comercializáveis". Assim, o rural silveirense recebe compradores de sua cultura, como também novos moradores em busca do cenário rural bucólico e imaginário vendido com seus produtos. Esses novos migrantes, oriundos dos núcleos urbanos das médias e grandes cidades brasileiras, são fugitivos do hiperconsumismo, promovido pela cultura global, e buscam novas experiências nas ruralidades silveirenses, mas também trazem transformações como: deixar de ter videiras e pipas para vinho em substituição por novas ruralidades como os campings, espaços destinados apenas para o lazer, não mais para moradia ou cultivos agrícolas. Os novos migrantes são moradores pendulares, em muitos casos, usam as propriedades para os momentos de sossego e lazer e trabalham e produzem sua renda em outros municípios vizinhos.

Para De David (2019), há uma dualidade no que diz respeito à ruralidade: de um lado o rural produtivo e do outro o rural patrimônio. Porém, no processo de aculturação digital que vem devorando a diversidade planetária, principalmente às profissões e os modos de vida, o rural patrimônio além de ser consumido é modificado. Para o autor, ele é “[...] o espaço de proteção da natureza e dos seus recursos, de contemplação da paisagem singular e da valorização da diversidade sociocultural e de seus habitantes, seus modos de vida e seus saberes-fazeres originais.” (DE DAVID, 2019, p. 285).

Nesse contexto, os elementos que identificação um modo de vida se (re)formulam e o rural ganha novas representações sociais que mediam e mediaram a vida comunitária e individual dos sujeitos. As reflexões de Santos (2008, p.158) explicam que "[...] muda o mundo e, ao mesmo tempo, mudam os lugares. Os eventos

\footnotetext{
${ }^{7}$ Entrevista realizada com morador A, entrevistado por Ana Carla Lenz em 06 de maio de 2019.

Geopauta, Vitória da Conquista, ISSN: 2594-5033, V. 4, n. 2, 2020, (p. 208-226) http://periodicos2.uesb.br/index.php/geo Este é um artigo de acesso aberto sob a licença Creative Commons da CC BY
} 
operam essa ligação entre os lugares e uma história em movimento e é por ele (lugar) que o mundo é percebido empiricamente". A todo o momento, novas possibilidades culturais surgem ou recomeçam, acentuadas pelas TIC, que aproximam lugares e culturas, mas que também aceleram o processo de transformação dos modos de vida locais, principalmente, por influenciarem os sistemas de ensino formais e não formais.

Foto 3 - Antiga Brizoleta - Escola Rural da Linha Seis Norte de Silveira Martins

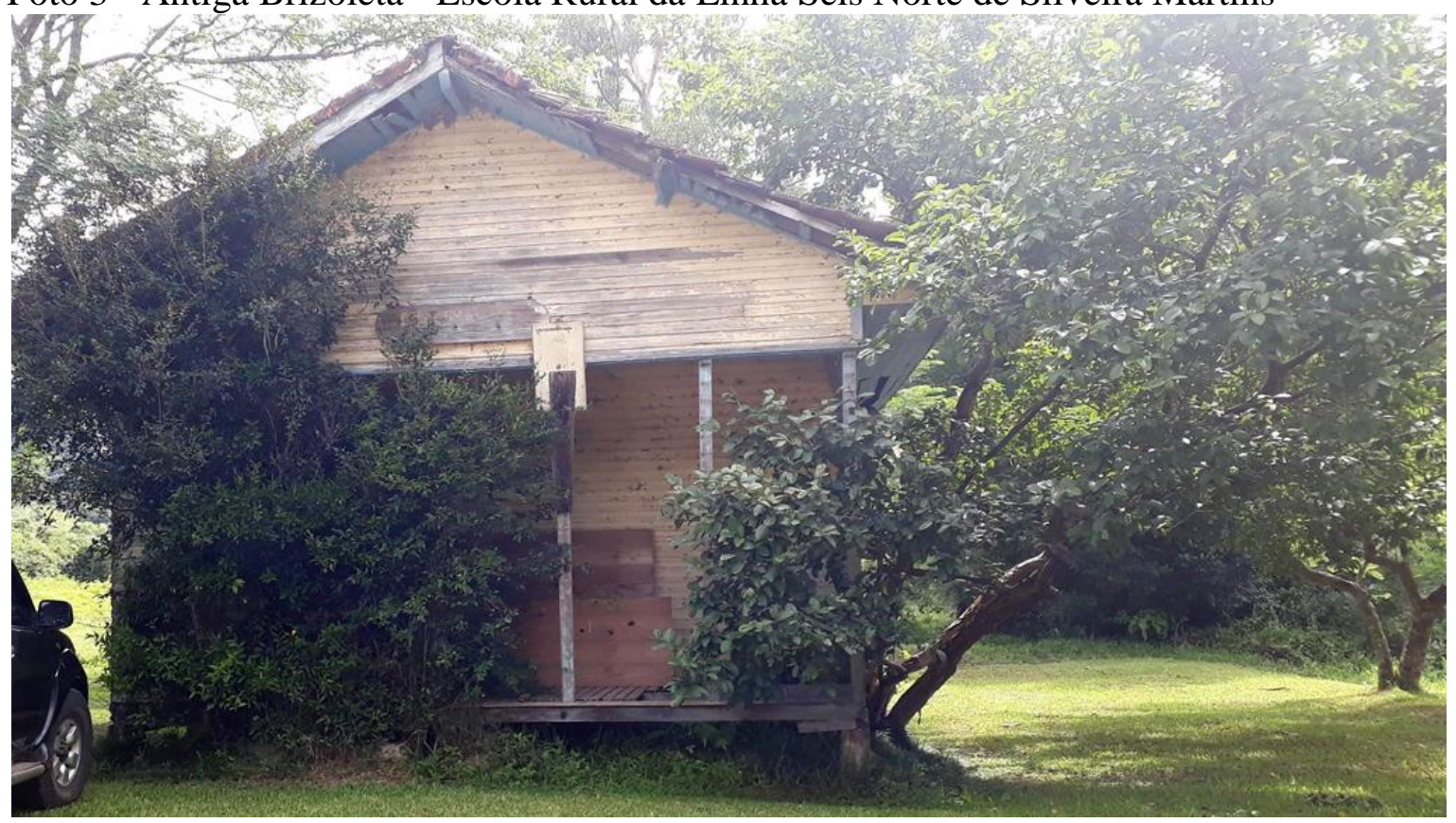

Fonte - LENZ, A. C. (Fevereiro de 2019. Silveira Martins/RS).

À educação dos silveirenses é agregado um conjunto de regras, rituais, mitos e ritmo de ordem religiosa católica e cultural. À educação sempre foi umas das preocupações dos núcleos familiares e do poder público. Preocupação impressa na espacialização dos espaços de socialização, o qual geralmente é/era composto pela capela, salão de festas, cemitério e pela escola. As escolas das áreas rurais do município com o avanço da modernidade, provedora do êxodo rural, foram fadadas ao esquecimento como revela Cesar De David (2014) e a Foto 3 demonstra.

Com a migração das famílias para as cidades e a redução da taxa de fecundidade, o campo também se esvaziou de crianças e jovens. A política nacional de nuclearização das escolas, privilegiando $\mathrm{o}$ transporte dos estudantes até a escolas - polo, levou ao fechamento de muitas escolas do campo. No Brasil, segundo os dados do Censo Escolar do INEP (Instituto Nacional de Pesquisa Educacionais Anísio Teixeira), 37.776 estabelecimentos de ensino rurais foram fechados nos últimos 10 anos. As escolas que promoviam a educação dos filhos dos agricultores e, além disso, na maioria dos casos, serviam de 
referência e integração às comunidades rurais, também se tornaram taperas. (DE DAVID, 2014, p. 86).

Os símbolos da modernidade contribuíram para o fechamento das escolas rurais, como destacou De David (2014), e também, favoreceu a desconfiguração das dinâmicas tradicionais propagadas por meio dos saberes e fazeres das populações rurais do município, pois o homem e a mulher do campo se afastaram das escolas, a qual perdeu a sua caracterização inicial. Assim, as ruralidades, impregnadas de conhecimentos herdados adquiridos através das experiências vividas no cotidiano, de difícil formalização sendo, portanto, difíceis de serem comunicadas e que requerem meios informais de comunicação deixaram de ser transmitidas no meio educacional formal. Isso ocorre devido não estarem escritas em lugar algum, pois habitam somente as memórias dos sujeitos que as exercitam através das práticas de trabalho cotidianas, desta forma elas vão se perdendo ao longo do tempo, a Foto 4 apresenta um desses conhecimentos.

Foto 4 - A carneação comunitária no interior do município de Silveira Martins.

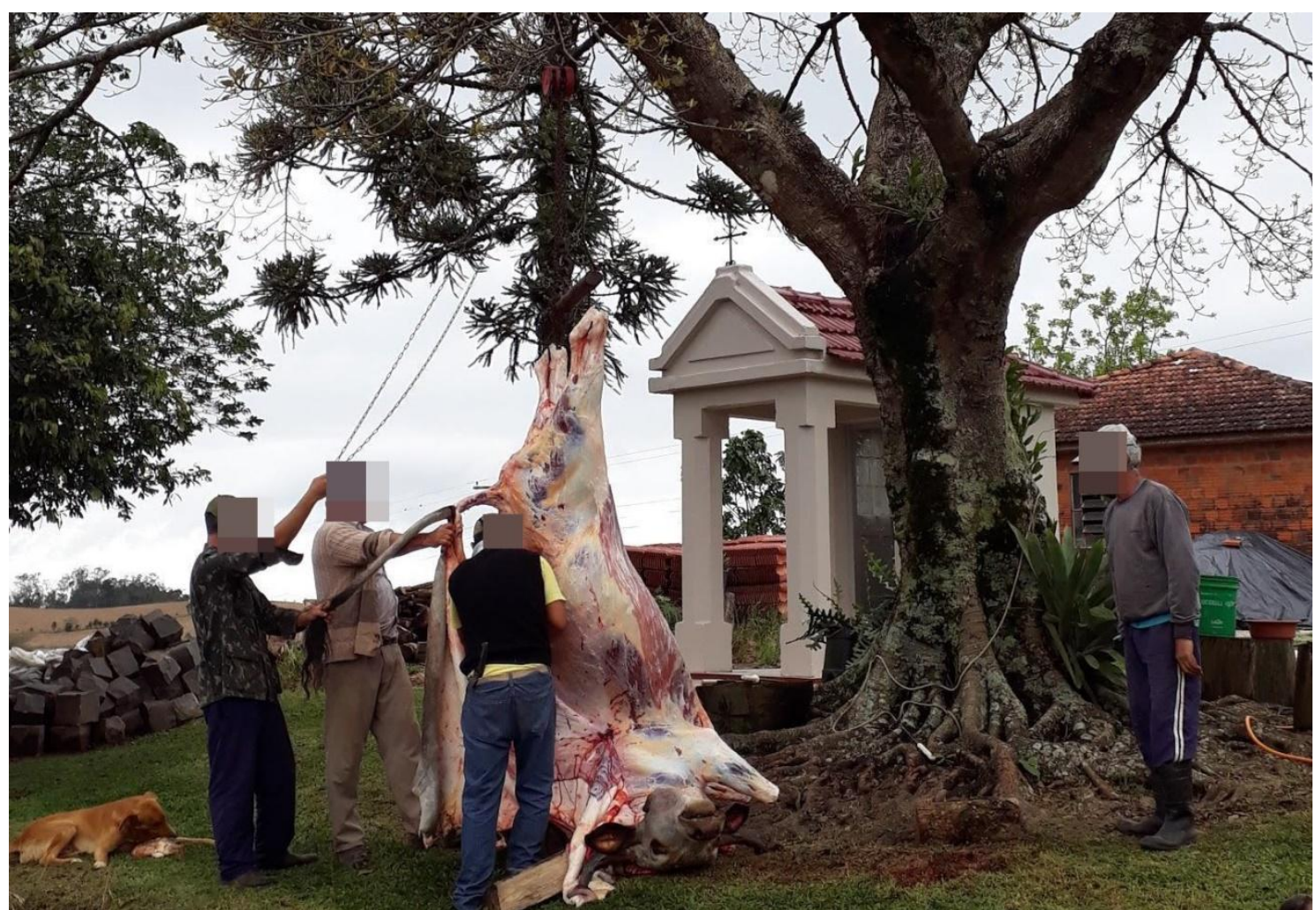

Fonte - LENZ, A. C. (Outubro de 2019. Silveira Martins/RS).

As narrativas que tecem a história apresentada na imagem da fotografia 4, revelam que "[...] o animal se enforcou ao tentar passar a cerca", observam que é um acontecimento tido como "natural", algo corriqueiro, mas deixam claro que o 
sangramento deve ser feito, logo, até uma hora após a morte, para não comprometer a carne, “[...] aprendi com o meu avô [...]” (informação verbal) ${ }^{8}$. Na cena vários conhecimentos herdados foram exercitados desde o chamar os vizinhos para realizar a carneação, o lugar preciso do corte para a sangria, saber pendurar o animal na árvore, além de toda a desossa e corte da carne em pedaços para fritar, assar ou dar como alimento aos animais.

As ruralidades são impregnadas desse tipo de conhecimentos. Elas, geralmente, são planejadas pelos sujeitos, por isso exigem identificação, armazenagem e atividades comunicacionais para sua manutenção. Porém, estão deixando de ser comunicadas, em virtude das facilidades do mundo. Para Byung-Chul Han (2018), nesse contexto, as relações são substituídas pelas conexões. O filósofo alerta que a comunicação digital é somente visual, contribuindo para perda de todos os sentidos e que se vive uma fase da comunicação global das likes sem valorar o real. Desta forma, os saberes e fazeres são apagados da memória ou (re)configurados para se adaptarem aos novos tempos e padrões de consumo, ou são substituídas por elementos da globalização compartilhados por meio das TIC.

Assim, o rural tido como, exclusivamente, produtivo e agrícola se configura com novas realidades que visam à valorização de um conjunto de elementos de natureza social que, Carneiro (2012) classifica como "ruralidades contemporâneas". Para a autora, elas, as "ruralidades contemporâneas" são encontradas nas localidades rurais onde ocorre a revalorização dos elementos da cultura local, por meio da incorporação de novos valores, hábitos e técnicas. A busca de áreas rurais para moradia, para o descanso e o lazer, muitas vezes, devido à imagem que habita o imaginário popular, construída no período da revolução industrial, de que o rural é um lugar com uma beleza cênica que expressa um mundo natural, em oposição às cidades e ao urbano, tidos como lugares de condições de vida insalubre, colabora com o processo.

A agroindustrialização dos saberes e fazeres locais de Silveira Martins é um exemplo de ruralidade contemporânea. Os produtos elaborados com base em características artesanais, como o grostoli, agnoline e a cuca ${ }^{9}$, geralmente, processados na cozinha domésticas das famílias, estão sendo industrializados por meio das

\footnotetext{
${ }^{8}$ Entrevista realizada com morador B, entrevistado por Ana Carla Lenz em 18 de outubro 2019.

${ }^{9}$ Ver mais detalhes em Lenz (2020. Festividades religiosas e socialização em espaços rurais: o caso de Silveira Martins/RS. (Dissertação de Mestrado). Programa de Pós-Graduação em Geografia. Santa Maria: Universidade Federal de Santa Maria, 2020.
} 
agroindústrias. Elas aparecem como importante alternativa de renda para as famílias, além de oferecer vantagens competitivas aos produtores, diante da diferenciação dos seus produtos frente ao consumidor e, também, constituem importantes estratégias de reversão ao quadro do êxodo rural no município e região, de acordo com Guimarães e Pinheiro (2018, p. 50-51).

Os ingredientes na panela da fotografia da Figura 5 são para a produção de cucas e pães em uma das agroindústrias familiares espalhadas pela paisagem de Silveira Martins. A depoente $\mathrm{C}$ revela que uma parte da renda de sua família vem da venda dos produtos fabricados em seu pequeno estabelecimento. Acrescenta que é uma receita típica da cuca do local feita com fermento caseiro, produzido através da fermentação da batata-inglesa, "fermento de batata" ${ }^{10,}$, que aprendeu com sua avó e sua mãe, saber e fazer que passou aos filhos. Mas, somente ela e o marido trabalham na agroindústria, eventualmente uma das filhas ajuda. Observa que não terá sucessão para o seu negócio, nem para o seus saberes e fazeres tradicionais, porque os seus filhos "preferem arrendar as terras e viver em Santa Maria"(informação verbal) ${ }^{11}$.

Foto 4 - As mãos que amassam: o saber-fazer tradicional

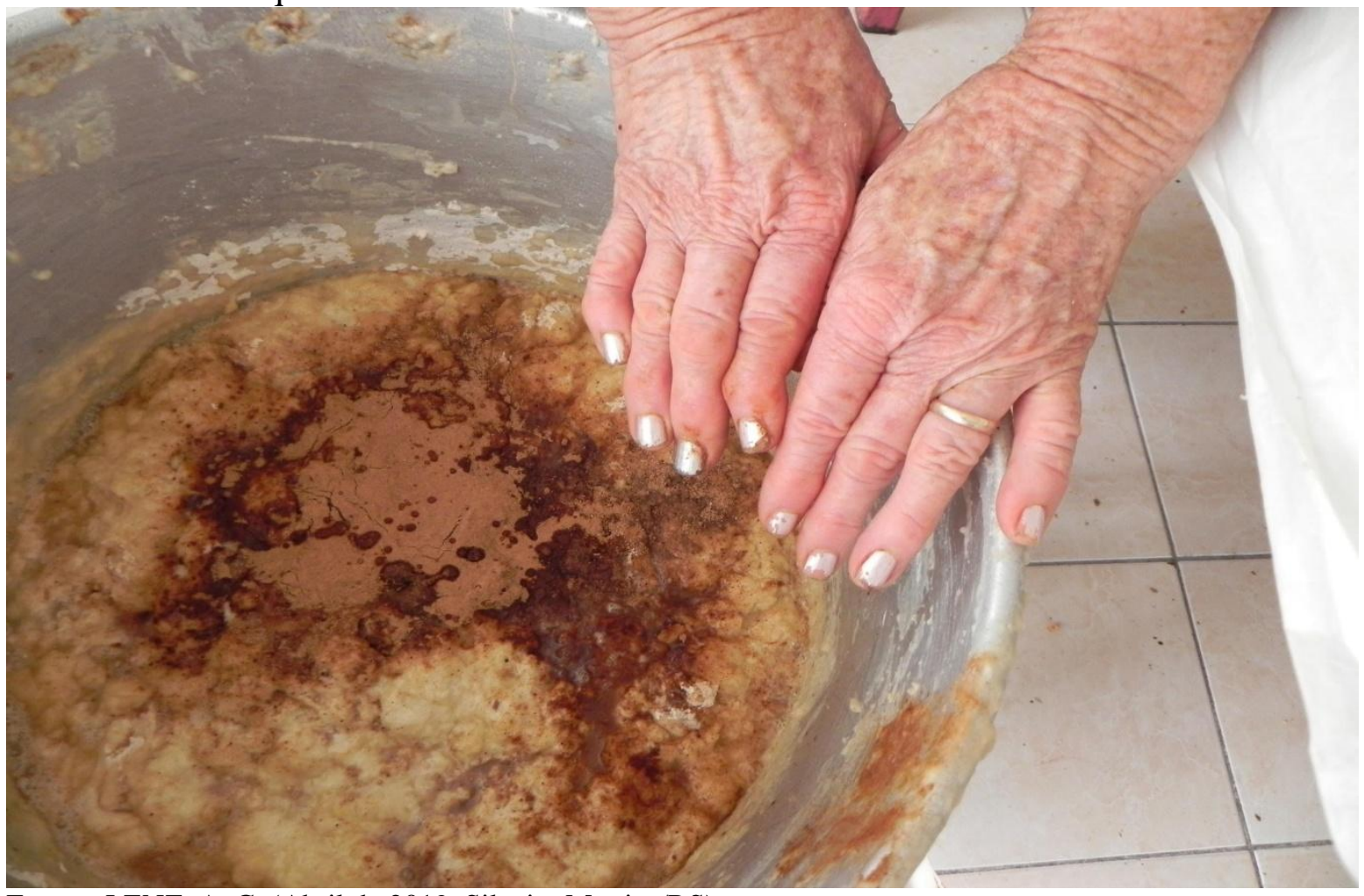

Fonte - LENZ, A. C. (Abril de 2019. Silveira Martins/RS).

\footnotetext{
${ }^{10} \mathrm{O}$ registro mais antigo é de $3.700 \mathrm{AC}$, mas sua origem provavelmente está relacionada com o início da agricultura.

${ }^{11}$ Entrevista realizada com morador C, entrevistado por Ana Carla Lenz em 27 de abril 2019.
}

Geopauta, Vitória da Conquista, ISSN: 2594-5033, V. 4, n. 2, 2020, (p. 208-226) http://periodicos2.uesb.br/index.php/geo Este é um artigo de acesso aberto sob a licença Creative Commons da CC BY 
A pele envelhecida e a deformação dos dedos devido à artrite reumatoide mostram que o tempo agiu sobre o corpo humano. Mas, não sobre a memória do saberfazer tradicional do descendente do imigrante italiano, ruralidade que permanece viva nas práticas diárias da depoente $\mathrm{C}$, que diz ser uma das poucas pessoas que ainda reproduz a receita com o fermento de batata no espaço rural de Silveira Martins. Além de observar que as famílias da agricultura familiar, na atualidade, compram pães e cucas dos "mercados ambulantes ${ }^{12}$ ". Cabe lembrar que a transmissão do conhecimento ocorre por meio de um ato linguístico, onde um comunica e o outro recebe o comunicado. Entretanto, no contexto descrito pela depoente, no diálogo, hoje, no meio rural, geralmente falta uma das pessoas na interação comunicativa, ou se tem, não prática o comunicado, assim o mesmo cai no esquecimento e, por fim, acaba desaparecendo ou sendo substituído por "ruralidades contemporâneas".

A cuca é um saber tradicional local, é uma das ruralidades que identifica os silveirenses assim como o vinho, ou seja, fazem parte do acervo de símbolos culturais que identificam as comunidades rurais do município. Ela vem sofrendo um processo de mudança devido à modernização das técnicas de produção e a falta de descendência. Tendo em vista que as ruralidades são a estrutura de "um espaço habitado por pequenas comunidades humanas, com valores mútuos e história comum que giram ainda em torno da fidelidade e do pertencimento a um meio, a um território e à família" (MEDEIROS, 2017. p.181). Medeiros (2017. p, 181) acrescenta, também, que na ruralidade "se reencontra uma dinâmica distinta e práticas sociais, culturais e econômicas fundadas sobre a proximidade, a convivialidade, a ajuda e a cooperação".

Conhecimentos que de acordo Guimarães e Pinheiro (2018) são

[...] gerados em condições singulares, a partir da arte presente de cada família, impulsiona e orienta atividades de elaboração de alimentos, como um produto único, ligado a um modo de vida que, passado de geração a geração entre as famílias, constituem um universo produtivo específico, ancorado em bases técnicas artesanais, mão de obra familiar e formulação (receitas) tradicionais (GUIMARÃES; PINHEIRO, 2018, p.47-48).

Em vista dos argumentos apresentados sobre os saberes e fazeres das ruralidades de Silveira Martins se entende que a falta de descendência e a mercantilização das ruralidades, como: os alimentos tradicionais, já mencionados, contribuem para a

\footnotetext{
${ }^{12}$ Pessoas que vendem produtos alimentícios no meio rural utilizando seus veículos próprios.
} 
descaracterização desses elementos e não mais se tornam fontes de diferenciação para atrair consumidores de diferentes culturas para as localidades rurais e, mesmo fomentando a permanência dos sujeitos no campo, estão sendo substituídos. Cabe transcrever as reflexões de De David (2019, p.285), quando destaca que a ruralidade vai além do rural agrícola, é um conjunto de atividades, funções e expressões de uma população impressas na paisagem. Se as ruralidades se tornam homogêneas aos demais espaços, pede-se as referencias dos saberes e fazeres locais e perde-se o interesse dos visitantes em conhecer a cultura herdada, bem como potencializa-se a sua perda enquanto memória e patrimônio imaterial dos lugares.

\section{Considerações Finais}

Silveira Martins faz parte da Quarta Colônia de Imigração Italiana do Rio Grande do Sul, fundada em 19 de maio de 1877 na região centro-oeste do Estado, ocupada por imigrantes italianos oriundos das regiões do norte da Itália, e no presente por seus descendentes, o que confere a espacialidade uma característica predominantemente agrícola até os dias atuais, mas com uma nova roupagem, a do agronegócio. O município tem a sua configuração inicial pautada em três fatores: na geografia do terreno, na imigração italiana e na Igreja Católica Apostólica Romana, a qual influenciou diretamente a divisão territorial, a política e a educação e se mantém atuante nos mesmos segmentos.

No processo de interação entre homem/meio e homem/homem saberes e fazeres foram adaptados, desenvolvidos e transmitidos entre gerações, como a sangria ou carneação, a cuca e o cultivo de uva e produção do vinho. Os mesmos se transformaram em referências identitárias da população silveirense, principalmente àquela que possui traços étnicos italianos e os que têm forte vinculo com o meio rural. Mas, na atualidade, com a inserção da cultura globalizada, por meio das novas TIC, essas ruralidades estão sofrendo um processo de (re/des)configuração, processo que está contribuindo para o esvaziamento de pessoas do campo e favorecendo a (re/des)apropriação dos lugares pelos descendentes de italianos.

Infere-se que Silveira Martins é rural, a sua paisagem é fortemente marcada pelas ruralidades e pelos símbolos do catolicismo. Porém, existem algumas unidades de paisagem com maior expressividade que ratificam a imagem de que o rural é predominante. São espaços portadores de saberes e fazeres desenvolvidos nos núcleos 
familiares e nos espaços de socialização de difícil formalização por não estarem escritos em lugar algum, por esse motivo a ele é atribuído valor mercantil atraindo visitantes e consumidores dos mesmos. Destaca-se que, na atualidade, os jovens estão se afastando do processo, mas que muitos possuem uma ligação de enraizamento com o lugar apesar de não praticarem os saberes e fazeres herdados dos imigrantes italianos.

Por fim, conclui-se que um modo de ser e de viver pautado em saberes e fazeres comunitários, com hábitos e costumes bem definidos, ou seja, impregnados de historicidades, encontrados no meio rural estão sendo transformados e substituídos por modos de produção industrializados. Todavia, muitos costumes ainda resistem às influências da modernidade. Transcrevê-los colabora para o despertar de uma sensibilização de valorização da cultura local e da agricultura familiar, bem como permite que suas memórias não sejam completamente apagadas pela cultura globalizada. Assim, tecer um olhar sobre Silveira Martins produzindo textos e relatando contexto é uma forma de preservar e difundir a sua cultura, bem como expor o imaginário mistificado sobre as ruralidades que não mais vigoram ou sobre àquelas que lutam cotidianamente para serem mantidas por quem domina os saberes e fazeres típicos do colonizador local.

Referências:

BRASIL. IBGE. Censo Demográfico de 2010. Disponível em:www.sidra.ibge.gov.br\&amp;gt. Acesso em: 10 janeiro 2019.

BARICHELLO, Cesar Augusto. Patrimônio Cultural Religioso e Negociação da Identidade do Imigrante da Colônia Imperial de Silveira Martins e Região Central do Rio Grande do Sul. In: Dissertação. (Dissertação de Mestrado) Apresentada ao Curso de Mestrado Profissionalizante em Patrimônio Cultural da Universidade Federal de santa Maria - UFSM/RS, 2010.

CARNEIRO, Maria José. Ruralidades contemporâneas: modos de viver e pensar o rural na sociedade brasileira. Rio de Janeiro: Mauad X, FAPERJ, 2012.

DE DAVID, Cesar. A geografia agraria e as paisagens rurais. In: MARAFON, Gláucio José; CHELLOTI, Marcelo Cervo; PESSÔA, Vera Lúcia Salazar. (Orgs.). Temas em Geografia Rural. Rio de Janeiro: EdUERJ, 2019.

GIRON, Loraine Slomp; HÉREDIA, Vania Beatriz Merlotti. História da imigração italiana no Rio Grande do Sul. Porto Alegre: EST, 2007.

GUIMARÃES, Gisele Martins, PINHEIRO, Rogério Oliveira. Patrimônio cultural e produção artesanal de alimentos: o saber fazer em sistemas de produção da Quarta Colônia. In: Saberes tradicionais e artesanato: expressões culturais do campo brasileiro. DE DAVID, Cesar \&amp; VARGAS, Daiane Loreto de. (Orgs.). São Leopoldo: Oikos, 2018. 
HAN, Byung-Chul. Hoje o indivíduo se explora e acredita que isso é realização. Disponível em: https://brasil.elpais.com/brasil/2018/02/07/cultura/1517989873 086219.html. Acessado em: 12 de novembro de 2019.

KOZENEESKI, Éverton de Moraes. Considerações sobre a modernização da agricultura. In: Dinâmica do espaço agrário : velhos e novos territórios: NEAG 10 anos / Rosa Maria Vieira Medeiros, Michele Lindner, organizadoras. - Porto Alegre : Evangraf, 2017.

LENZ, Ana Carla. Festividades religiosas e socialização em espaços rurais: o caso de Silveira Martins/RS. 140 páginas. (Dissertação de Mestrado). Programa de Pós-Graduação em Geografia. Santa Maria: Universidade Federal de Santa Maria, 2020.

MANFIO, Vanessa; BENADUCE, Gilda Maria Cabral. Quarta Colônia de Imigração Italiana/RS: Uma abordagem sobre a cultura e identidade. In: Geosul, Florianópolis, v. 32, n.65, p. 260-273, set./dez. 2017.

MASSEY, Doreen. Pelo espaço. Rio de Janeiro: Bertrand Brasil, 2008.

MEDEIROS, Rosa Maria Vieira Medeiros; MEDEIROS, Raphael Vieira; LIDNER, Michele. Vinho e território: um caminho indenitário comum. In: MARAFON, Gláucio José; CHELLOTI, Marcelo Cervo; PESSÔA, Vera Lúcia Salazar. (Orgs.). Temas em Geografia Rural. Rio de Janeiro: EdUERJ, 2019.

MEDEIROS, Rosa Maria Vieira. Ruralidades: novos significados para o tradicional rural. In: Dinâmica do espaço agrário: velhos e novos territórios : NEAG 10 anos/Rosa Maria Vieira Medeiros, Michele Lindner, organizadoras. - Porto Alegre: Evangraf, 2017.

PAZUCH, Giovane. Imigração Italiana na Colônia de Silveira Martins -RS: deslocamentos, redes familiares e relações de poder (1877-1922). In: Anais. 30 Simpósio Nacional de História -Recife, 2019.

ROVANI, Franciele Francisca Marmentini; VIEIRA, Márcio. Potencial Social do município de Silveira Martins, RS: Contribuição ao Zoneamento Ecológico- Econômico. IN: Caminhos de Geografia: Uberlândia, v. 17, n. 58 Jun/2016.

SAQUET, Marcos Aurélio. Os tempos e os territórios da colonização italiana: o desenvolvimento econômico da Colônia Silveira Martins (RS). Porto Alegre: EST, 2003.

SANTOS, Milton. Técnica, espaço e tempo: globalização e meio técnico- científico informacional. 2.ed. São Paulo: Hucitec, 2008.

\section{Agradecimentos}

À Coordenação de Aperfeiçoamento de Pessoal de Nível Superior - CAPES. 